\title{
BIOPOLÍTIC
}

ORMALIZAÇÃO IDENTITÁ M SEXUALIDADES INDÍGE! 


\section{BIOPOLÍTICA E NORMALIZAÇÃO IDENTITÁRIA EM SEXUALIDADES INDÍGENAS}

\section{PAULO DE TÁSSIO BORGES DA SILVA}

UNIVERSIDADE DO ESTADO DO RIO DE JANEIRO 


\title{
BIOPOLÍTICA E NORMALIZAÇÃO IDENTITÁRIA EM SEXUA- LIDADES INDÍGENAS
}

\section{Resumo}

Dentro do roteiro biopolítico de normalização da identidade indígena, o dispositivo de sexualidade tem incidido de maneira velada em meio aos biopoderes, fazendo por vezes a sexualidade passar despercebida na discussão. No que concerne às populações indígenas brasileiras, não falar da sexualidade ou falar dentro de uma classificação heterossexual, passou a ser o caminho de regulação identitária com ênfase no viés da pureza étnica. Neste sentido, proponho com este artigo analisar como o dispositivo de sexualidade age e está presente nas identidades indígenas. Para tanto, opero com os estudos pós-estruturais e pós-coloniais, entendendo que estes permitem deslocamentos possíveis na tentativa de se construir uma reflexão e um texto sem fechamentos.

Palavras-chave: Biopolítica, Normalização, Identidade Sexualidades Indígenas.

\section{BIOPOLITICS AND IDENTITY NORMALIZATION IN INDIGE- NOUS SEXUALITIES}

\begin{abstract}
Within the biopolitical script of normalization of indigenous identity, sexuality has actuated in a veiled manner in the midst of biopowers, thus causing sexuality sometimes to be kept unnoticed in the discussion. As far as Brazilian indigenous populations are concerned, not to talk about sexuality or to talk only in terms of a heterosexual context has become the way of regulating identity with an emphasis on the bias of ethnic purity. In this sense, I propose with this article to analyze how the device of sexuality acts and presents in the indigenous identities. For that, I work with poststructural and postcolonial studies, understanding that they allow possible displacements in the attempt to construct a reflection and a text without closures.
\end{abstract}

Keywords: Biopolitics, normalization, identity, indigenous sexualities. 


\section{BIOPOLÍTICA Y NORMALIZACIÓN IDENTITARIA EN SEXUA- LIDADES INDÍGENAS}

\section{Resumen}

En el guion biopolítico sobre normalización de la identidad indígena, el dispositivo de sexualidad se ha enfocado de manera velada en medio de los biopoderes, haciendo que la sexualidad pase desapercibida en la discusión. En lo concerniente a poblaciones indígenas brasileras, no hablar de sexualidad o hablar de ella dentro de una clasificación heterosexual, ha sido el camino para regular la identidad con un sesgo en el discurso de la pureza étnica. En este artículo propongo analizar cómo el dispositivo de sexualidad actúa y está presente en las identidades indígenas. Para ello, opero con los estudios post-estructurales y poscoloniales, pues entiendo que permiten desplazamientos posibles en una tentativa de construir una reflexión y un texto sin cierres.

Palabras clave: Biopolítica, Normalización, Identidad, Sexualidades indígenas.

Endereço do autor para correspondência: Universidade do Rio de Janeiro-UERJ. Programa de pós-graduação em educação-Proped, rua São Francisco Xavier, 524, grupo 12.037-F, CEP: 20550-900, Rio de Janeiro-RJ.

paulodetassiosilva@yahoo.com.br 


\section{CONSIDERAÇÕES INICIAIS}

Em mais de uma década de pesquisas com povos indígenas brasileiros ${ }^{2}$, em particular, povos indígenas da região nordeste, as expressões de gênero e sexualidades tem me feito refletir acerca de seus lugares e não lugares, bem como suas fronteiras e cruzamentos no que veio sendo delineado e normalizado como identidade indígena. É neste contexto de discussão, que busco neste artigo analisar como o dispositivo de sexualidade age e está presente nas identidades indígenas no Brasil.

Ao operar com esta reflexão faço uso do conceito de biopolítica, não pretendendo realizar uma análise fundacional de 1974 a 1979, período em que Foucault se dedica ao conceito, não obstante, a biopolítica será tratada aqui como:

[...] tecnologia que se instala, se dirige à multiplicidade dos homens, não na medida em que eles se resumem em corpos, mas na medida em que ela forma, ao contrário, uma massa global, afetada por processos de conjunto que são próprios da vida, que são processos como nascimento, morte, a produção, a doença, etc. (Foucault 1999:289).

Foucault traz a biopolítica para dizer das mudanças que ocorrem a partir do século XVIII na racionalização governamental, em que outrora se colocava no individuo (disciplina), para uma descoberta populacional no gerenciamento da vida. Nesta reflexão, o poder se desloca do ato de fazer morrer, do suplício, para o ato do fazer viver, instaurando biopoderes que ultrapassam o controle corpo individual (anátomo- -política), ou quando senão o articula dentro de uma população (biopolítica). O dispositivo de sexualidade nesta análise talvez seja o que melhor ilustra essa engenharia em que o poder se organizou, sendo este dispositivo permeado de uma relação próxima da disciplina com a biopolítica, operando na captura e governo de corpos individuais e em contigentes populacionais.

Como dispositivo trabalho com as proposições de Agamben (2005), tomando este como:

[...] um conjunto heterogêneo que inclui virtualmente: (linguístico e não-linguístico, discursos, instituições, leis, medidas de segurança, proposições filosóficas) [...] que tenha de algum modo a capacidade de capturar, orientar, determinar, interceptar, modelar, controlar e assegurar os gestos, as condutas, as opiniões e os discursos dos seres viventes. (Agamben 2005:9,13)

É nesta maquinaria heterogênea, relacionando-a com a sexualidade, que estarei refletindo as capturas, as tentativas de controle e normalização da identidade indígena. Como itinerário de escrita estarei abordando como a categoria indígena foi enunciada no Brasil, apresentando em seguida a mestiçagem e a hibridização como reguladoras de identidade, entrando na análise sobre biopolítica e normalização identitária em sexualidades indígenas, pensando em seguida sexualidades indígenas indecidíveis. O texto se insere nos estudos realizados na linha de pesquisa "Currículo: sujeitos, conhecimento e cultura" e no projeto "Currículo, Subjetividade e Diferença”, coordenado 
pela professora Elizabeth Fernandes Macedo, do Programa de Pós-Graduação em Educação da Universidade do Estado do Rio de Janeiro - PROPED/ UERJ, e no Órgão de Educação e Relações Étnicas com Ênfase em Culturas Afro-brasileiras e Indígenas - ODEERE da Universidade Estadual do Sudoeste da Bahia-UESB.

\section{A Invenção da Categoria Indígena}

No cenário brasileiro, a construção da categoria indígena ou índio se deu numa captura identitária para se referir aos povos que habitavam o que hoje é tratado como território brasileiro. A explicação mais corrente trata do equívoco geográfico de Colombo ao pensar que tinha chegado às "Índias", somando-se algumas reflexões de autores decoloniais (Quijano 2005) que remetem a uma leitura geopolítica entre Europa e América, tratando a questão como um modelo de dominação baseado na raça, em que o Ocidente passa a ser referência, expandindo mais tarde para análises que englobam os Estados Unidos, utilizando como termo o "euroamericanismo". Além do termo índio, a Coroa portuguesa criou os termos Tapuia e Tupi para se referir aos indígenas que eram amigos ou inimigos da Coroa. Neste caso, os Tapuia ${ }^{3}$ eram considerados os índios bravios, todos aqueles que fossem contra a expansão, e os Tupi, amigos e aliados da Coroa (Silva 2009:24).

A categoria indígena tem sido questionada recebendo críticas de etnias que procuram não se vincular a ela. Entre as críticas está o fato da categoria não dar conta das mais de duas centenas de etnias que vivem atualmente no Brasil. Há caso de etnias que não reconhecem a categoria indígena, e também não aceitam a nominação étnica dada a ela, como é o caso dos Maxakali, que negam ambas as nominações (como indígena e como Maxakali), se afirmando como Tikmũ $\tilde{u n}^{4}$.

Sem a pretensão de trazer aqui uma historicidade da categoria indígena, uma vez que não se pretende recorrer a certo fundacionismo, vale dizer que antes da década de 1980 havia um rechaçamento de tal categoria por parte dos indígenas, sendo vista como categoria colonial no relacionamento com o Estado-Nação. Foi somente em 1978, quando no governo Geisel um projeto ameaçou a condição de tutelados pelo Estado, prevendo a emancipação indígena e a desobrigação da União com seus territórios e tradições, que houve uma identificação em torno da categoria indígena, passando a adotá-la como identidade de referência. Neste caso, a partir da reiteração de uma norma que outrora era tida como depreciativa, começam a se aglutinar etnias em torno da categoria indígena que trato aqui como algo imaginado. Para tanto, volto-me ao conceito de "comunidades imaginadas" de Benedict Anderson (2008), que utiliza o termo para pensar a ideia de nação como uma "comunidade política imaginada". Nestes termos, "ela é imaginada porque mesmo os membros da mais minúscula das nações jamais conhecerão, encontrarão, ou sequer ouvirão falar da maioria de seus companheiros, embora todos tenham em mente a imagem viva da comunhão entre eles" (Anderson 
2008:32). Sobre esta teorização, Appadurai (2004) vem colocando que "a imaginação tornou-se um campo organizado de práticas sociais, uma maneira de trabalhar (tanto no sentido do labor, como no da prática culturalmente organizada) e uma forma de negociação entre redes de ação (indivíduos) e campos de possibilidade globalmente definidos" (Appadurai 2004:48-49).

Operando com Appadurai (2004), ouso remeter a categoria indígena e as etnias às comunidades imaginadas, que disputam e negociam significados e significações dentro de uma rede de imaginários. Logo, estas etnias imaginadas não apenas estariam reiterando imaginários nacionais do que se constrói discursivamente sobre elas, mas fissurando esta discursividade o tempo todo na composição de paisagens. Pensar a partir de paisagens com Appadurai (2004) indica "[...] que estas não são relações objetivamente dadas que parecem o mesmo de todos os ângulos de visão, são construções profundamente perpectivadas, infletidas pela localização histórica, linguística e política de diferentes tipos de actores" (Appadurai 2004:50-51). A proposta reflexiva de Appadurai (2004) pode ser ilustrada mediante uma rede de paisagens, em que olhares e movimentos compõem perspectivas diversas, obedecendo de certa forma, um controle daquilo que consigo enxergar e determinar como paisagem. Neste sentido, as categorias indígena e etnia nada mais são do que uma dada paisagem num regis- tro discursivo que não se encerra, ao contrário, é um fluxo contínuo que reitera sempre na diferença.

Trabalhar a ideia de etnia como uma comunidade imaginada pode ser potente para se escapar de teorias que remetem a identidade vinculada a um território, a fraturas e partilhas históricas e a repertórios culturais linguísticos. Neste caminho,

[...] o paradoxo central da política étnica no mundo actual é que os factores primordiais (sejam eles de linguagem, de cor da pele, de vizinhança ou de parentesco) se globalizaram. Ou seja, os sentimentos, cuja maior força está na sua capacidade de fazer da intimidade um estado político e da localidade um palco para a identidade, vão se espalhando por espaços vastos e irregulares à medida que os grupos se deslocam, mas mantendo-se ligados entre si através de sofisticados processos de comunicação (Appadurai, 2004:61).

As tentativas de desafios à política étnica encapsulada não significam estar contra os movimentos identitários, ao contrário, são percepções de um terreno que pode se mover noutras fronteiras. Não ousaria nem partir para a defesa de uma traição identitária, uma vez que tal proposta remeteria ao alicerce de uma originalidade. Mover a política étnica ao caminho do imaginário é dar conta de "[...] que este é um mundo em que tanto os pontos de partida como os pontos de chegada estão em fluxo cultural e por isso a busca de pontos de referência estáveis quando são feitas as opções de vida pode ser muito difícil" (Appadurai 2004:65). 
Mestiçagem e Hibridização como reguladores de identidades

Alimentando a produtividade da regulação de uma identidade indígena primeira, "pura", os escapes do emoldurado matricial, categorizados em mestiço e caboclo serviram durante muito tempo para dizer de "perdas culturais" atreladas ao modelo de etnicidade sustentado pela antropologia e o judiciário brasileiro. É o caso das populações indígenas do nordeste, tratadas durante muito tempo pela antropologia (até início da década de 1990) e o indigenismo brasileiros como "integrados no meio regional", "mesclados com perdas de elementos tradicionais" (Galvão 1979), "resíduos da população indígena", "magotes de índios desajustados" (Ribeiro 1970). Ao estudar o povo Huarpe na Argentina, Katzer (2009) aponta:

Baseadas no exotismo e na pureza cultural, as etnografias elaboradas durante quase a totalidade do século XX em que aparece o selvagem como a figura discursiva constitutiva da construção de seu objeto, desobjetivaram como sujeito étnico aqueles povos e culturas que, como os Huarpes, evidenciavam "mestiçagem" e "perda dos traços tradicionais” (Katzer 2009:59; tradução livre).

Neste sentido, em certas ocasiões, laudos periciais antropológicos, etnografias e outros processos de judicialização tem servido nesse emaranhado de discursos para legitimação de uma categoria indígena fixa a um repertório cultural, dentro de uma territorialidade que se deseja fechada. Vale registrar os sinais de "pureza" étnica reificados pelos discursos, estando muitas vezes vinculados à fala de uma língua indígena. Logo, aqueles que não falam mais suas línguas são tratados como mestiços, cabôclos, misturados. Tais discursos atuam na construção de um imaginário social de um índio que não se pode hibridizar, ultrapassando os limites que regulam sua pureza.

Ao analisar a mestiçagem com os Huarpe na Argentina, Katzer (2009) a considera um dispositivo biopolítico textual de normalização racial, tendo os censos e as etnografias "como atos de poder, como textos constitutivos e constituintes da forma de poder governamental" (Katzer 2009:61; tradução livre). Vale ressaltar a análise da autora sobre a relação da categoria hibridização e mestiçagem no que chama de reorganização nacional e "guerra entre as raças". Segundo ela, a hibridização é vista no contexto argentino como algo positivo uma vez que se considera "como híbrido nascente, o produto da fusão intraeuropéia e da assimilação do nativo-crioulo pelo estrangeiro, atribuindo-lhe a origem das 'nações modernas"' (Katzer 2009:65; tradução livre), enquanto o mestiço é utilizado como subjetivação ou adjetivação, referindo-se a um subproduto interno transitório. Desta forma, "a mestiçagem é conceitualizada como um produto puro resultante da degeneração de uma raça - a sub-raça - e sua crescente absorção, assimilação por outra, a suprarraça" (Katzer 2009:69; tradução livre). Para a autora, ao lado da mestiçagem enquanto condição de "vestígio do passado", "rastros indíge- 
nas em declinação seletiva", está arbitrariamente a desidentificação indígena, sendo a categoria indígena utilizada apenas para se referir aos indígenas do passado, o que permite uma territorialidade argentina racialmente normalizada, livre do problema aborígene (Katzer 2009:69

Acredito que pensar a mestiçagem como dispositivo biopolítico pode ser profícuo em análises no contexto brasileiro. Não obstante, até mesmo pelo trato acerca das questões indígenas na Constituição Federal de 1988, a relação da mestiçagem que outrora serviu para integrar tais populações a um imaginário de cidadão nacional brasileiro, tem servido para a construção de outros modos de ser indígena, não anulando aqui o espectro das perdas culturais que ronda tal categoria. Para evidenciarmos um pouco mais a capilaridade deste espectro me volto a algumas questões do mundo Guarani, partilhado por um jovem desta etnia, que chamarei de Avá (nome fictício). O jovem em questão é filho de mãe não indígena com um pai guarani, vendo-se no conflito de não ser visto como "Guarani puro", mas mestiço pela sua família e seus pares. Segundo Avá, para se purificar - uma vez que se considera um Guarani mestiço -, sua avó disse que ele precisava casar com uma indígena, não podendo mais casar com uma "branca". Perguntei a Avá se a indígena precisava ser Guarani ou poderia ser de outra etnia; ele respondeu que eu tinha lhe deixado com dúvidas e não sabia me dizer. Percebi que a maneira como seus parentes Guarani o tratavam - "Guarani mestiço" - o incomodava, sendo esta nomenclatura utilizada para deixá-lo menor em alguns momentos da aldeia, sendo justificativa para impedi-lo de ocupar alguns cargos e funções.

Pesquisando indígenas no Nordeste brasileiro, Oliveira (1998) coloca que é somente na década de 1975, após a Reunião Brasileira de Antropologia realizada em Salvador, que a antropologia se volta para esta população, demandada por questões territoriais colocadas pela Fundação Nacional do Índio - FUNAI, o que estimulou grupos de trabalhos sobre os Pataxó e Kiriri na Bahia. Foram destes trabalhos que começaram a surgir grupos como a Associação Nacional de Ação Indigenista - ANAI e Programa de Pesquisas sobre Povos Indígenas do Nordeste Brasileiro - PINEB, numa tentativa de reunir pesquisas do que chamaram de índios do nordeste. Segundo Oliveira (1998), "a unidade dos 'índios do nordeste’ é dada não por suas instituições, nem por sua história, ou por sua conexão com o meio ambiente, mas por pertencerem ao Nordeste, enquanto conglomerado histórico e geográfico" (Oliveira 1998:51-52). Para o autor, uma característica dos textos destes grupos era trazer a expressão "índios misturados", encontrada em documentos oficiais históricos que tratavam sobre estes povos; contudo, o tratamento dado a essa questão ficou situado na discussão com os atributos negativos que os desqualificavam da ideia de pureza étnica. Oliveira (1998) chama atenção para o desconforto da FUNAI em trabalhar com os índios do Nordeste, tendo em vista sua incorporação nas economias e sociedades regionais. Di- 
ferente das populações indígenas que o órgão indigenista estava acostumado a trabalhar, em situações de fronteira territoriais com povos que se manifestavam diferente dos não índios.

No Nordeste, contudo, os "índios" eram sertanejos pobres e sem acesso à terra, bem como desprovidos de forte contrastividade cultural. Em uma área de colonização antiga, com as formas econômicas e a malha fundiária definidas há mais de dois séculos, o órgão indigenista atuava apenas de maneira esporádica, respondendo tão-somente às demandas mais incisivas que recebia. Mesmo nessas poucas e pontuais intervenções, o órgão indigenista tinha de justificar para si mesmo e para os poderes estaduais que o objeto de sua atuação era efetivamente composto por "índios", e não por meros "remanescentes" (Oliveira 1998:52-53).

O mal estar da FUNAI em atender as populações indígenas do Nordeste era sintomático ao que tais populações representavam. No entanto, a pressão de tais populações, acirrada pelo fenômeno da chamada etnogênese ou reetnização, levou a emergência de etnias conhecidas citadas nos documentos históricos, bem como a reinvenção de etnias a partir de fluxos culturais distintos. Para pensar os fluxos culturais com o seus cortes e capturas que originam as etnias, Oliveira (1998) nos propõe pensar uma etnologia dos índios misturados, sugerindo "abandonar imagens arquitetônicas de sistemas fechados e se passar a trabalhar com processos de circulação de significados, enfati- zando que o caráter não estrutural, dinâmico e virtual é constitutivo da cultura" (Oliveira 1998:69).

Num caminho um pouco diferente, analisando um grupo que se denomina afroindígena no Sul da Bahia, o grupo cultural Umbandaum, e os Tupinambá da Serra do Padeiro, comunidade indígena tida como misturada por apresentar traços afros e cultuarem os encantados do candomblé, Goldman (2015) apresenta uma teoria etnográfica da (contra)mestiçagem. Para o autor, a (contra)mestiçagem não se dá "no sentido de uma recusa da mistura em nome de uma pureza qualquer, mas no da abertura para o caráter analógico, e não digital, e para o elemento de indeterminação que qualquer processo de mistura comporta" (Goldman 2015:654).

Percebe-se que Goldman (2015) lança mão do indeterminado, do imprevisto, e toma de empréstimo um conceito derridiano, o indecídivel. Parece-me que tal proposta nos permite um diálogo melhor com as aberturas e os escapes que compõem a questão identitária, percebendo que a mistura ou a hibridização não precisa estar fixada, podendo esta ser gerúndio, um contínuo estar sendo. Neste sentido, questionando uma identidade indígena brasileira homogênea e acreditando que "[...] as identidades são sempre forjadas num terreno movediço, em entre-lugares culturais, híbridos e complexos" (MACEDO 2006: p. 350), que me dirijo ao pós-estruturalismo da filosofia da différance de Derrida (2001). Parto da ideia de que o discurso em 
que a identidade se constrói é flutuante e inconcluso, e que o sujeito se constrói negociando dentro de um sistema de diferenças, podendo “[...] pensar o processo de diferenciação para além de qualquer espécie de limites" (Derrida 2001:14). Para Derrida (2001),

A atividade ou a produtividade conotada pela/da différance remete ao movimento gerativo no jogo das diferenças. Essas últimas não caíram do céu e nem estão inscritas de uma vez por todas em um sistema fechado, em uma estrutura estática que uma operação sincrônica e taxonômica pudesse esgotar (Derrida 2001:33).

Neste sentido, “[...] a identidade nunca é a priori, nem um produto acabado; ela é apenas e sempre o processo problemático de acesso a uma imagem da totalidade" (Bhabha 2013: p. 94). Acerca desta perspectiva, cabem ao diálogo as contribuições de Hall (2003) quando nos faz pensar a cultura e seus processos inventivos:

O que esses exemplos sugerem é que a cultura não é apenas uma viagem de redescoberta, uma viagem de retorno. Não é uma "arqueologia". A cultura é uma produção. Tem sua matéria-prima, seus recursos, seu "trabalho produtivo". Depende de um conhecimento da tradição enquanto "o mesmo em mutação" e de um conjunto efetivo de genealogias. Mas o que esse "desvio através de seus passados" faz é nos capacitar, através da cultura, a nos produzir a nós mesmos de novo, como novos tipos de sujeitos. Portanto, não é uma questão do que as tradições fazem de nós, mas daquilo que nós fazemos das nossas tradições. Paradoxalmente, nossas identidades culturais, em qualquer forma acabada, estão à nossa frente. Estamos sempre em processo de formação cultural. A cultura não é uma questão de ontologia, de ser, mas de se tornar (Hall 2003:40).

Neste sentido, é nesse "tomar-se" culturalmente que a cultura deixa de ser algo estático, meramente transmitido, tendo o sujeito seu lugar de agência nas fronteiras e cruzamentos da fabricação de si.

\section{Biopolítica e normalização identitária em Sexualidades Indígenas}

Dentro do roteiro biopolítico de normalização da identidade indígena, o dispositivo de sexualidade tem incidido de maneira velada em meio aos biopoderes, fazendo por vezes a sexualidade passar despercebida na discussão. A pouca abordagem nos estudos etnológicos acerca do tema, como apontei em outro estudo sobre a homossexualidade indígena (Silva 2016) e como vem apontando Fernandes (2015), Tota (2013) e McCallum (2013), revela lugares ainda pouco confortáveis nas etnografias, como aponta Cariaga (2015) em suas pesquisa com com os jovens Kaiowa e Guarani na Reserva Indígena de Dourados - RID do Mato Grosso do Sul. Segundo Cariaga (2015), um acordo tácito foi construído ao ser questionado a sexualidade do antropólogo e dos indígenas, neste sentido, pontua: "[...] assumir a minha homossexualidade diante dos meus in- 
terlocutores e expor a homossexualidade deles colocava em jogo questões que não eram costumeiramente tratadas no âmbito das pesquisas acadêmicas, pois os três já haviam colaborado em muitas dessas" (Cariaga 2015: p. 445).

A entrada no campo indígena a partir de outras temáticas tem sido muitas vezes o caminho inicial para depois adentrar às questões das sexualidades indígenas. Para Cariaga (2015),

[...] o tema esbarra em questões que entrelaçam limitações e moralidades de como a etnologia indígena tem neglicenciado interlocuções com pesquisas antropológicas sobre relações de gênero e performatividade entre os gêneros, realizadas em sua maioria em "sociedades complexas", que teriam poucos efeitos para reflexões sobre as transformações ameríndias (Cariaga 2015:442).

Acredito que as poucas análises neste campo, além do já apontado por Cariaga (2015) acima, cai naquilo que venho operando ${ }^{5}$ numa perspectiva Derridiana (Derrida 1994), de uma vinculação espectral de "perdas culturais" em torno das identidades indígenas, nas performatividades de gêneros e sexualidades que destoam da heterossexualidade. Nesta perspectiva, negocia-se um bloco de indianidade homogêneo, numa lógica de adequação em que o Estado brasileiro definiria como índio mais ou menos "puro", sendo essa definição requisito de acesso às políticas públicas e programas indigenistas pelas etnias. É neste ponto que me interessa aqui analisar como o dispositivo de sexualidade age numa biopolítica de normalização da identidade indígena.

Em se tratando da população indígena, diferentes são os dispositivos de regulação e normalização, o que numa análise do conceito construído por Foucault se vincularia a pontos como política e saúde, política e guerra (incluindo aqui o dispositivo de raça), política e sexualidade, política e segurança e política e economia. Nesta reflexão, interessa-me abordar a biopolítica na sua relação com a saúde (por esta interseccionar questões de gênero) e com a sexualidade, relacionando com os povos indígenas que venho tendo experiências de trabalho e pesquisa ${ }^{6}$.

A relação da política com a saúde é uma das primeiras reflexões de Foucault na construção de seu conceito de biopolítica, sobretudo, a partir da relação que se estabelece entre o Estado e a medicina no controle da população, naquilo que seria normal ou anormal, bem como na regulação de uma faixa etária saudável para ser tido como uma força laboral produtiva ou não, dermarcando categorias geracionais e sistemas de seguridade social. Neste sentido,

O controle da sociedade sobre os indivíduos não se efetua somente pela consciência ou pela ideologia, mas também no corpo e pelo corpo. Para a sociedade capitalista é o bipolítico que importava acima de tudo, o biológico, o somático, o corporal. O corpo é uma realidade biopolítica; a medicina é uma estratégia biopolítica (Foucault 2001:209).

Um exemplo da medicina como estratégia biopolítica em contextos indígenas que ilustro neste trabalho é o 
processo de esterilização de mulheres Hã Hã Hãe, denunciado pela mídia e na pesquisa de Souza (2007) com mulheres Hã Hã Hãe na Reserva Indígena Caramuru-Paraguaçu, Itajú do Colônia, Sul da Bahia. O caso ocorreu em 1998, quando a denúncia de esterilização em massa de mulheres Hã Hã Hãe em idade fértil ganhou os noticiários. O jornal o Globo em 1998 trouxe em sua notícia o trecho:

$\mathrm{Na}$ aldeia Bahetá, não há sequer uma índia grávida, nem têm nascido mais crianças. Espremidos entre a cidade de Itaju do Colônia -- a $110 \mathrm{Km}$ de Ilhéus -- e propriedades de grandes fazendeiros que se apoderam de parte da reserva, os Pataxó estão vendo sua nação minguar. (....). Não é difícil imaginar o que levou as mulheres casadas de Bahetá a fazerem a esterilização. Os índios vivem numa pequena área, de um alqueire de terra seca, improdutiva e sem alimentos. O rio Colônia, que corta a aldeia, vem sendo represado pelos fazendeiros da região e já não tem mais água nem peixes suficientes. Os índios passam fome e sobrevivem da cesta básica fornecida pelo governo. Apesar das dificuldades, quatro anos depois das primeiras cirurgias (feitas em 1994), o povo Pataxó Hãhãhãi mostra aparente arrependimento pela decisão antes tomada, e que na época parecia ser a salvação para quem não tinha o que dar de comer às crianças (O Globo 1998:1).

A estratégia biopolítica de controle da população indígena pelo processo de esterilização não é somente um método de controle percebido no Nordeste brasileiro, conforme matéria também publicada no jornal O Globo em $01 \mathrm{de}$ dezembro de 2012, em que noticia o investimento dos EUA para Fujimori esterilizar 314 mil mulheres no Peru. A matéria traz ${ }^{7}$ :

Elas não foram as únicas vítimas desse capítulo ainda pouco conhecido da etapa de barbárie política que prevaleceu na América do Sul na segunda metade do século XX. O governo Fujimori esterilizou, por cirurgia de ligadura de trompas, 314.605 mulheres com idade entre 15 e 49 anos, na maioria pobres e analfabetas, indígenas residentes em áreas remotas da selva amazônica. É o que indicam documentos do Plano Populacional, iniciado em meados de 1990. Nessa época, as mulheres em idade fértil representavam $41 \%$ da população rural peruana e eram comuns as famílias com mais de cinco filhos [...]Fujimori instituiu uma política de Estado, executada no sistema público de saúde e direcionada a ao estrato populacional mais pobre. (O Globo 2012:1).

A relação do Estado com a medicina, como podemos observar nas duas notícias, mostra como esta estrátegia biopolítica é adotada no controle e regulação da população indígena, não sendo o processo de esterilização o único procedimento adotado. A pesquisa de Barcellos (2008) com as mulheres tupinikim revela que o desprestígio com a medicina indígena, a produção de medidas para dificultar o parto pelas parteiras da aldeia, substituindo por obstetras dos hospitais, alterou o quadro populacional tupinikim com famílias numerosas, onde " [...] a média por mulheres antes de se iniciar o quarto ciclo 
territorial Tupiniquim era oito filhos" (Barcellos 2008:364). Tais empreendimentos também se situam na ordem de um discurso higienista colonial, provocando mudanças nos cotidianos das populações, como relata Barcellos (2008) com os Tupinikim:

Um outro evento de menor importância mas que contribuiu para a alteracao do corpo da mulher foi a construcao de banheiros pela FUNASA. O formato das fossas ou mesmo o uso da mata, onde as mulheres para fazerem as suas necessidades fisiológicas ficavam de cócoras, possibilitava o fortalecimento da musculatura da pelve e da parte interna da coxa, contribuindo para a sua preparacao física para os partos naturais (Barcellos 2008:365).

A partir do que foi apresentado acima, podemos analisar que o gerenciamento biopolítico a partir da saúde é perpassado por dispositivos de controle mais amplos como a esterilização, e um controle do corpo mais silencioso, que pode ser lida aqui como uma "anátomo- política”, provocada por mudanças no cotidiano das populações indígenas. Sobre este aspecto Farhi Neto (2007) pontua: “ A biopolítica aparece como a prática política de apreensão social dos corpos dos indivíduos, no capitalismo; e a medicina, como instrumento desse controle político" (Farhi Neto 2007:20). É neste campo de apreensão dos corpos e como instrumento de controle político que a biopolítica também se revela nas sexualidades indígenas. É na relação entre política e sexualidade que, "[...] a biopolítica encontra na sexualidade dos indivíduos - sexualidade que a própria biopolítica induz, incita, produz -, um suporte de regulação da população" (Farhi Neto 2008:53).

Farhi Neto (2008) ao investigar o dispositivo de sexualidade e os mecanismos de sexualização nos traz que estes:

[...] remontam, em parte, à direção de consciência da pastoral cristã, no século XVI, e são deslocadas progressivamente, tornando-se mais complexas, para as instituições pedagógicas, para a família burguesa e, finalmente, para toda a sociedade, constituem um dos principais instrumentos políticos de regulação das populações (Farhi Neto 2008:53).

No caso das populações indígenas brasileiras não falar da sexualidade ou falar dentro de uma classificação heterossexual, passou a ser o caminho de regulação identitária com ênfase no viés da pureza étnica. Em outras discussões no campo das sexualidades indígenas, analisando primeiro a homossexualidade, estabeleço que há uma "[...] relação de poder em que o "dominador" estabelece uma tipologia ideal de indianidade, tendo o "dominado" que se adequar a esta na possibilidade de acessos que este pode proporcionar (políticas públicas, programas, dentre outros)" (Silva 2016:71). Neste mesmo caminho, Trevisan (1986), fazendo algumas considerações sobre o Povo Krahó, no Estado do Tocantins, aponta que os homens solteiros e casados desta etnia realizam práticas homoeróticas. Para Trevisan (1986), há a “[...] crença de que, no Brasil, os índios contraem gripe, doenças venéreas e 
homossexualismo no contato com os brancos" (Trevisan 1986:96).

Pensando Sexualidades Indígenas Indecidíveis

De certa maneira, a negação de performatividades não heterossexuais em contextos indígenas tem servido a discursos que buscam provar a ausência da homossexualidade, por exemplo, em comunidades tradicionais, alegando tais performatividades como "anormais”. Neste ponto, Farhi Neto (2008) nos atenta que:

O dispositivo de sexualidade é o mecanismo de poder que encontra nas perversões o sustento do seu aprofundamento. A deflagração de um estado latente de sexualidade aberrante permite estabelecer os pontos aos quais o poder se agarra, para controlar a sociedade e os comportamentos individuais (Farhi Neto 2008:54).

É na busca por compreender como o dispositivo de sexualidade tem tentado regular e normalizar as identidades indígenas no Brasil que tenho perseguido trabalhar com categorias que não fossem colonizadoras das sexualidades indígenas, entendendo que o termo "homossexualidade indígena" leva a uma concepção binária com a "heterossexualidade indígena", e optado, também dentro de uma perspectiva derridiana (Derrida 1997), o uso do termo "sexualidades indígenas indecidíveis", percebendo estas como "condições de possibilidades". A esse termo voltam-se ainda reflexões do que se vem chamando de um "queer indígena" (Fernandes 2013, 2015, 2016), categoria esta que o movimento Two-Spirits já tem criticado, apontando-o como mais um conceito colonizador. Acerca deste ponto, Pereira (2012) também reflete os possíveis limites da teoria queer nos trópicos, limites estes que vão além da geopolítica do conhecimento, com o termo em inglês. Para Belaunde (2015),

\begin{abstract}
Algumas pesquisas recentes nas terras baixas da América do Sul tentam estender pontes entre as teorias da etnologia indígena e as teorias contemporâneas da sexualidade, especialmente a teoria queer, o que não é uma tarefa simples de se realizar. É difícil compatibilizar o foco aberto aos diálogos intelectuais surgidos nos estudos das sociedades urbanas e pós-coloniais com o foco mais específico da etnologia, em que as especificidades da língua e das pequenas variações de localidade podem ser muito importantes (Belaunde 2015:408).
\end{abstract}

Nesta reflexão de uma aderência à teoria queer, coloco o desafio e a problemática ao se eleger o termo "queer indígena" para se referir a mais de 300 etnias indígenas em território brasileiro com performatividades de gênero e sexualidades as mais distintas entre si. Neste sentido, diante das reflexões, opto por ora, em tratar a questão como "sexualidades indígenas indecidíveis", deixando como "não-conceito", "condições de possibilidades".

Vale dizer que, de maneira alguma se nega aqui que, o fato de se pensar as sexualidades indígenas como "indecidíveis", também faz parte de uma regulação e tentativa de normalização, sendo discursivamente mais uma tentativa de caputura localizada naquilo 
que Foucault chama de "dispositivo de sexualidade”. Para Farhi Neto (2007):

O dispositivo de sexualidade não é o poder que esconde, que reprime, que recalca, em nome da civilização burguesa, o sexo, e com ele nosso sentido, nosso corpo e nossa identidade autênticos. Pelo contrário, o dispositivo de sexualidade produz a sexualidade. E é no afã de conhecer uma suposta autenticidade do nosso desejo, que nos tornamos os sujeitos desse dispositivo. (Farhi Neto 2007:55)

Neste sentido, odotar sob rasura a categoria "sexualidades indígenas indecidíveis" só não será colonial desde que dialogue com as fronteiras e os cruzamentos em que os povos indígenas se encontram e desejam estar. Para tanto, é preciso estar atento que por mais que uma teoria seja pós-estruturalista, queer, pós-colonial, entre outras, suas possibilidades de enquadramentos não estão descartadas, logo, algo sempre estará escapando, haverá sempre o "indecidível”.

\section{CONSIDERAÇÕES INCONCLUSAS}

Ao debruçar-me sobre a diversidade de gênero e sexual em contextos indígenas, venho percebendo as fronteiras e os cruzamentos no que veio se normalizando como indígena. Neste sentido, uma vinculação a gêneros não binários e a sexualidades não heterossexuais é tida como perdas culturais e mistura identitária, negociando-se um bloco de indianidade homogêneo, numa lógica de adequação em que uma rede de discursos definem o que vem a ser índio mais ou menos "puro", obedecendo uma regra de inteligibilidade baseada num fetiche identitário calcificado, sendo essa definição requisito de acesso às políticas públicas e programas indigenistas pelas etnias. Sobre tais questões venho trabalhando a partir da noção de uma vinculação espectral (Derrida 1994) de perdas culturais em torno da categoria indígena.

Acerca deste modelo de etnicidade fundado em traços culturais inscritos numa tradição, sendo tida nos laudos periciais antropológicos como verdades identitárias, Bhabha (2013) nos aponta:

O reconhecimento que a tradição outorga é uma forma parcial de identificação. Ao reencarnar o passado, este introduz outras temporalidades culturais incomensuráveis na invenção da tradição. Esse processo afasta qualquer acesso imediato a uma identidade original ou a uma tradição 'recebida' (Bhabha 2013: p. 21).

Pensar com Bhabha (2013) a reiteração da tradição é dizer que toda tradução é falsa e qualquer tentativa de fechamento em torno de uma originalidade é impossível, uma vez que o próprio ato de reiteração é suplementador.

Nesta reflexão procurei apresentar tentativas biopolíticas de normalização identitária em sexualidades indígenas a partir do espectro das perdas culturais, sendo importante dizer que as tentativas de normalização da identidade indígena pelo dispositivo de sexualidade não estão somente em discursos que vinculam a uma "heterossexualidade compulsória” (RICH 1993), mas tam- 
bém em análises herméticas e neocoloniais que ainda trabalham com referenciais que tem servido mais a contextos ocidentais, do que as sociedades indígenas. Neste sentido, continuar operando sob rasura com o indecidível pode ser potente na construção de reflexões decoloniais.

\section{NOTAS}

${ }^{1}$ Misturar, tornar-se mestiço, assumir-se como caboclo: são atitudes que nem sempre são vistas com bons olhos nos diálogos que tratam sobre indígenas. Num campo em que a construção da identidade se faz por meio da fixidez em repertórios culturais, em partilhas e capturas em fatos históricos, ou quando senão em emolduramentos territoriais, mover a discussão para outros terrenos pode contribuir na compreensão das relações de poder que normalizam a identidade indígena no Brasil, bem como evidenciar outros processos de subjetivação que perpassam outros lugares dentro desta questão. Para tanto, opero com os estudos pós-estruturais e pós-coloniais, entendendo que estes permitem deslocamentos possíveis na tentativa de se construir um texto sem fechamentos. Não obstante, diante de um campo (etnologia) que teve sua construção a partir de teorias estruturalistas, os deslizes do caminhar por estas teorias podem se fazer presentes, o que não julgo ser um problema uma vez que o caminho de uma pesquisa se dá entre fronteiras possíveis de negociações.

${ }^{2} \mathrm{O}$ emprego da categoria povo ao tratar de indígenas é reconhecido pela Convenção 169 da Organização Internacional do Trabalho - OIT de 1989, ratificada no Brasil em 2002 pelo Congresso Nacional e promulgada pelo Decreto $\mathrm{n}^{\circ} 5.051 / 2004$, admitindo o direito de autodeterminação cultural e étnica nos marcos do Estado Brasileiro.

${ }^{3}$ Foi convencionado pela Associação Brasileira de Antropologia (ABA), desde 1953 que a primeira letra da grafia dos nomes tribais e ou grupos étnicos deve ser escrita com letra maiúscula, tanto para registrar os substantivos, quanto o adjetivo gentílico e mesmo quando contextualizados no plural, neste caso substantivos e adjetivos não flexionam, dispensando o emprego do "s".

${ }^{4}$ Os Tikmũ ũn são nomeados pela sociedade nacional como Maxakali. Segundo o censo do IBGE de 2010, os Tikmũ ũn possuem uma população de 1.500 pessoas, vinvendo no Nordeste de Minas Gerais, na fronteira com a Bahia. Paraíso (1994b) traz como hipótese de que os conhecidos Pataxó na atualidade, são clãs dispersos de uma mesma nação, em meio às suas reorganizações na história, assim como outros povos conhecidos como: Maxakali, Monoxó, Kumanaxó, Kutaxó, Kutatoi, Malali, Maconi e Amixokori.

${ }^{5}$ Apontei tais reflexões no paper apresentado no Seminário "Foucault na Amazônia? Sexualidades Indígenas", organizado pelo NanSI/PPGAS-MN/UFRJ, NAIPE/PPGSA-IFCH/UFRJ e CesTA/USP, em 2015, no Rio de Janeiro, organizado por Luisa Elvira Belaunde, Elsje Lagrou e Marina Vanzolini.

${ }^{6}$ Povos Pataxó, Pataxó Hã Hã Hãe, Tupinambá, Tupinikim e Guarani do ES.

7 http://oglobo.globo.com/mundo/eua-pagaram-para-fujimori-esterilizar-314-mil-mulheres-6886423 Acesso em 20/01/2017.

\section{REFERÊNCIAS}

Agamben, G. 2005. O que é um Dispositivo? Ilha de Santa Catarina: Outra Travessia (Tradução: Nilcéia Valdati). 
Anderson, B. 2008. Comunidades Imaginadas: reflexões sobre a origem e difusão do nacionalismo. São Paulo: Cia das Letras, (Trad. Denise Bottman).

Appadurai, A. 2004. Dimensões Culturais da Globalização: a modernidade sem peias. Lisboa: Editorial Teorema LTDA, (Trad. Telma Costa).

Barcellos, G. H. 2008. Desterritorialização e R-existência Tupiniquim: mulheres indígenas e o complexo agroindustrial da Aracruz Celulose. Minas Gerais: UFMG/Departamento de Geografia, (Tese de doutorado).

Belaunde, L. E. 2015. O estudo da sexualidade na etnologia. Cadernos de Campo 24:399-411. São Paulo.

Bhabha, H. K. 2013. O Local da Cultura. 2 ed. Belo Horizonte: Editora UFMG, (trad. Myriam Ávila, Eliana Lourenço de Lima Reis, Gláucia Renate Gonçalves).

Cariaga, D. 2015. Gênero e Sexualidades Indígenas: alguns aspectos das transformações nas relações a partir dos Kaiowa no Mato Grosso do Sul. Cadernos de Campo 24:441-464. São Paulo.

Derrida, J. 1997. A farmácia de Platão. Tradução de R. Costa. São Paulo: Iluminuras. 1994. Espectros de Marx. Tradução de A. Skinner. Rio de Janeiro: Relume. 2001. Posições. Belo Horizonte: Autêntica.

Farhi Neto, L. 2008. Biopolítica como Tecnologia de Poder. Revista Internacional Interdisciplinar INTERthesis 5(1). Florianópolis: UFSC.

Farhi Neto, L. 2007. Biopolítica em Foucault. Dissertação de Doutorado, Departamento de Filosofia, UFSC, Florianópolis.

Fernandes, E. R. 2013. Ativismo homossexual indígena e decolonialidade indígena: da teoria queer as críticas two-spirit. $37^{\circ}$ Encontro Anual da ANPOCS, SPG 16, Sexu- alidade e Gênero: espaço, corporalidades e relações de poder, Águas de Lindóia, SP.

Fernandes, E. R. 2015. Descolonizando Sexualidades: enquadramentos coloniais e homossexualidade indígena no Brasil e nos Estados Unidos. Tese de Doutorado, Programa de Pós-Graduação em Estudos Comparados sobre as Américas, Brasília.

Fernandes, E. R. 2016. Homossexualidade indígena no Brasil: um roteiro histórico-bibliográfico. Aceno 3(5): 14-38. Dossiê Diversidade Sexual e de Gênero em Áreas Rurais, Contextos Interioranos e/ou Situações Etnicamente Diferenciadas: novos descentramentos em outras axialidades.

Foucault, M. 2001. La naissance de la médecine social. Texto 196, in Dits et écrits. Vol. II. 1976-1988. Paris: Quarto Gallimard.

Foucault, M. 1999. Em Defesa da Sociedade. São Paulo: Martins Fontes.

Galvão, E. 1979. Áreas Culturais Indígenas do Brasil: 1900/1959, in Encontro de Sociedades. Rio de Janeiro: Paz e Terra, p. 193-228. Goldman, M. 2015. "Quinhentos Anos de Contato": por uma etnografia da (contra) mestiçagem. Mana, Rio de Janeiro, 21(3): 641-659.

Hall, S. 2003. Da Diáspora: Identidades e Mediações Culturais. Belo Horizonte: Editora UFMG.

Katzer, L. 2009. El Mestizaje como Dispostivo Biopolítico, in Pueblos Indígenas: interculturalidad, colonialidad, politica. Organizado por L. Tamagno. 1 ed. Buenos Aires: Biblios, p. 59-75.

Macedo, E. 2006. Currículo: Política, Cultura e Poder. Currículo Sem Fronteiras 6(2):98-113, Jul/Dez .

Mccallum, C. 2013. Notas sobre as categorias "gênero" e "sexualidade" e os povos indígenas. Cadernos Pagu 41:53-61.

O Globo 1998. Caderno País, 12. 30.08. 
O Globo 2012. Caderno Mundo, 01.12.

Oliveira, J. P. 1998. Um Etnologia dos’ Índios Misturados?? Situação colonial, territorialização e fluxos culturais. Mana 4(1): 47-77. Rio de Janeiro

Pereira, P. P. G. 2012. Queer nos Trópicos. Contemporânea - Revista de Sociologia da UFSCar 2(2):371-394. São Carlos.

Quijano, A. 2005. Colonialidade do poder, eurocentrismo e América Latina, in $A$ colonialidade do saber: eurocentrismo e ciências sociais. Organizado por E. Lander. Buenos Aires: CLACSO.

Ribeiro, D. 1970. Os Índios e a Civilização. Rio de Janeiro: Editora Civilização Brasileira.

Rich, A. 1993. Compulsory Heterosexuality and Lesbian Existence. in Adrienne Rich's Poetry and Prose. Editado por B. C. Gelp, e A. Gelp) New York/London: W.W. Norton \& Company.

Silva, P. T. B. 2016. Notas sobre a Homossexualidade num "Regime de Índio". Aceno 3(5): 50-72. Dossiê Diversidade Sexual e de Gênero em Áreas Rurais, Contextos Interioranos e/ou Situações Etnicamente Diferenciadas: novos descentramentos em outras axialidades..

Silva, P. T. B. 2009. A Educação Escolar Indígena no Processo de Revitalização Cultural Pataxó na Escola Estadual Indígena Kijetxawê Zabelê. Teixeira de Freitas: Universidade do Estado da Bahia - UNEB, (Monografia de Graduação).

Souza, J. M. A. 2007. Trajetórias Femininas Indígenas: Gênero, Memória, Identidade e Reprodução. Dissertação de Mestrado, Departamento de Antropologia, UFBA, Salvador.

Tota, M. 2013. Entre as Diferenças: Gênero, geração e sexualidades em contexto interétnico. Rio de Janeiro: Multifoco.
Trevisan, J. S. 1986. Devassos no Paraíso: a homossexualidade no Brasil, da Colônia à atualidade. 2 ed. São Paulo: Max Limonad.

Recebido em 06/02/2017

Aprovado em 05/08/2017 